free) which C. T. Linder has compiled is therefore timely and should prove most useful. The contents of the monograph consist of details of the different methods of temperature determination, together with tables and graphs of data useful in the practical application of those methods. First, the low-temperature scale is briefly outlined, and then in more detail the gas and vapour thermometers, the thermocouple and the resistance thermometer are discussed. Finally, the measurement of temperatures below $1^{\circ} \mathrm{K}$. is briefly considered, and the suggestion of Lawson and Long to use the Brownian motion, though not yet experimentally verified, is mentioned. The tables and graphs constitute nearly two-thirds of the monograph, and although the complete monograph is a photographic reproduction of typescript, the tables and graphs are exceptionally clear and easy to read. Every effort has been taken to make the material presented as up-to-date as possible. Table 2, consisting of seven pages, deals with the variation with temperature of the vapour pressure of helium and has been copied directly from material, dated June 1949, made available by the Royal Society Mond Laboratory, Cambridge.

\section{Astronomical Photographs from the Yerkes Observatory}

SINCE 1903 the Yerkes Observatory of the University of Chicago has been reproducing, in lantern slides, transparencies and prints, the original astronomical photographs made at Williams Bay. Within recent years, copies of photographs made at other observatories have been added to the collection, and these reproductions are sold by the University of Chicago Press. In "Astronomical Photographs", an illustrated catalogue edited by Thornton Page (pp. 36 ; Williams Bay, Wis. : Yerkes Observatory, 195I), the reproductions are listed and can be ordered by catalogue number from the Photographic Service Department, Yerkes Observatory, Williams Bay, Wisconsin. One hundred $3 \frac{1}{4}$ in. $\times 4$ in. slides for the use of teachers and lecturers are available, and at greatly reduced cost sixty selected slides are now offered in the 2 in. $\times 2$ in. size, and on $35 \mathrm{~mm}$. film strip, the former at 25 dollars for the sixty and the latter at 10 cents each. In addition to the set of selected slides for general use, the catalogue lists and describes slides and photographs illustrating specific research problems of modern astronomy and astrophysics-problems of the solar chromosphere and corona, of planetary atmospheres, of the origin of the solar system, of the aurora borealis, of lunar craters, of meteor and comet spectra, of interstellar clouds, of novæ and supernovæ, of the spectra of all types of nebulæ, and of galactic structure. The list finishes off with maps of neon and iron spectra, views of modern and historical instruments, and portraits of ninety famous astronomers.

\section{Petroleum Consumption and Production in Great Britain}

The Petroleum Information Bureau has recently issued a pamphlet (pp. 8; I.ondon: 29 New Bond Street, W.1; 1951), at the behest of the U.K. Petroleum Industry Advisory Committee, setting forth statistics on consumption of petroleum products; deliveries of motor spirit to dealers and commercial consumers; analysis of deliveries into consumption of gas, diesel and fuel oils; production of petroleum products from imported and indigenous crude and process oils; and indigenous materials made avail- able for distribution by the petroleum industry. From the statistics given it appears that, during 1950 , $5,195,173$ tons of motor spirit, including motor benzole, were consurmed in Great Britain. Considering that petrol rationing was not lifted until May 1950, this is a high figure, one, however, certain to be greatly exceeded for the current year. Total deliveries of gas, diesel and fuel oils for burning and power in the same year amounted to 5,337,791 tons. During the year Great Britain produced 949 tons of indigenous petrol by low-temperature carbonization, 130,177 tons of petrol and aviation spirlt by hydrogenation and 188,842 tons of refined benzole-not an unworthy record.

\section{Cambial Injuries in a Pruned Stand of Norway Spruce}

A Forestry Commission publication, Forest Record No. 4 (pp. 12; London: H.M. Stationery - Office, $1950 ; 9 \bar{d}$. net), by W. R. Day, is devoted to "Cambial Injuries in a Pruned Stand of Norway Spruce" and is based on an experiment made of pruning the side branches of Norway spruce with the object of raising the quality of timber and so the economic value of the crop. One of the pruning experiments was carried out in Drummond Hill Forest on Loch Tay-side, Perthshire, at four different times of the year-May, July, October and January. Unpruned control plots were maintained, and all the plots had been brashed up to a height of about $6 \mathrm{ft}$. 'The trees in the forest were planted in 1912 and were thirty-five years old when examined in 1947. In a summary of the research work undertaken, the author says that a severe case of bark necrosis occurred, owing to frost damage, usually after the pruning had taken place and either at the beginning or end of the growing season. The damage to the unpruned trees was much less severe. The wood made by the spruce is abnormal in that its cell walls are of a weak structure and tend to be insufficiently lignified, especially the late wood. A typical feature of these trees is that the annual ring ends abnormally, indicating that their growing season is unduly long considering the type of climate in which they grow. The experimental demonstration of the diagnosis put forward in this paper is under consideration. 'The technical difficulties are involved, and research will be required into the relationship between provenance of spruce seed, that is, of the variability of a species and the relative usefulness of its variations in any particular region. Research is also required in the type of wood developed in Great Britain and susceptibility to the type of injury here describeda matter of some importance, for the results might seriously affect the productive efficiency of future plantations.

\section{Chestnut Blight}

THE symptoms of chestnut blight, caused by the fungus Endolhia parasitica, are described and illustrated in colour in Booklet No. 3 of the Forestry Commission (pp. $4+4$ pl. ; London : H.M. Stationery Office; $1950 ; 2 s .6 d$. net). This is a disease of the sweet chestnut, Castanea sativa, which has not yet been found in Great Britain ; it has, however, caused very serious damage in the United States and is established in Italy and Spain. There is sufficient sweet chestnut in France to form a potential infectionbridge to the fairly extensive coppices of this tree in the south of England, and it is therefore highly desirable to recognize any possible occurrence in 